\title{
ANALISIS KESESUAIAN IDENTITAS DIAGNOSA KEPERAWATAN PADA PASIEN DI RUMAH SAKIT.
}

\author{
Nadia Febriani Br. Barus
}

Nadiafebriani001@gmail.com

Latar belakang: Diagnosis keperawatan harus ditingkatkan lagi didalam dipelayanan rumah sakit dan fasilitas kesehatan lainnya agar seragam, akurat, dan tidak ambigu. Penegakan diagnosis keperawatan sebagai salah satu komponen standar asuhan keperawatan perlu dilaksanakan dengan baik sebagaimana yang diamanahkan dalam undang-undang No.38 tahun 2014 tantang keperawatan pada pasal 30 bahwa dalam menjalankan tugas sebagai pemberi asuhan keperawatan, perawat berwenang menetapkan diagnosis keperawatan. Perawat sebagai penegak diagnosis yang harus memiliki kemampuan diagnosis yang baik sebagai dasar mengembangkan rencana intervesnsi keperawatan dalam mencapai peningkatan, pencegahan, penyembuhan dan pemulihan kesehatan klien Keperawatan merupakan bagian integral dari pelayanan kesehatan di Rumah Sakit, karena itu tujuan pelayanan perawatan merupakan salah satu bagian dari tujuan utama rumah sakit. Sesuai dengan UU No 44 tahun 2009 bahwa rumah sakit adalah institusi pelayanan kesehatan yangmenyelenggarakan pelayanan kesehatan perorangan secara paripurna yang menyediakan pelayanan rawat inap, rawat jalan dan gawat darurat. Karena itu, perawat sebagai ujung tombak pemberi pelayanan di rumah sakit dituntut untuk dapat memberikan pelayanan kesehatan yang bermutu, aman dan professional sesuai dengan perkembangan IPTEK kesehatan serta kebutuhan dan tuntutan masyarakat Mutu pelayanan keperawatan sebagai indikator kualitas pelayanan kesehatan menjadi salah satu faktor penentu citra institusi pelayanan kesehatan dimata masyarakat. Menurut Al assaf (2009) mutu dapat dicapai jika layanan yang terjangkau dapat diberikan dengan cara yang pantas dan hemat biaya. Layanan yang bermutu adalah layanan yag berorientasi pada pelanggan, tersedia terjangkau dan mudah didapat. Untuk mencapai mutu pelayanan yang baik bagi pasien diperlukan motivasi kerja yang tinggi dari seorang perawat. Motivasi adalah sesuatu di dalam diri manusia yang memberi energi, aktifitas, dan gerakan yang mengarahkan perilaku, untuk mencapai usaha tersebut sangat bergantung pada kemampuan seseorang untuk memuaskan berbagai kebutuhannya. Usaha merupakan ukuran intensitas kemauan seseorang. Apabila seseorang termotivasi yang bersangkutan akan berusaha keras meningkatkan penampilan kerja(Bernard, Berebson,\& A. Stieiner, Illyas, 2001). Motivasi seseorang akan timbul apabila diberi kesempatan untuk berusaha untuk mencapai hasil kerja yang baik dan mendapat umpan balik dari prestasi kerja yang telah dilakukan. Motivasi bertujuan untuk meningkatkan prestasi 
kerja bawahan dalam mencapai tujuan. Menurut Hasibuan (2005) pentingnya motivasi karena motivasi adalah hal yang dapat menyalurkan, dan mendukung prilaku manusia supaya mau bekerja giat dan antusias mencapai prestasi yang optimal. Menurut penelitian Andi (2008) tentang Analisis faktor-faktor yang berhubungan dengan motivasi kerja perawat pelaksana di RSUD Blambangan $65,59 \%$ perawat pelaksana memiliki motivasi sedang. Faktorfaktor yang melatar belakanginya adalah 98,92\% karena faktor instrinsik yaitu prestasi dan pengembangan diri, 67,74\% dan faktor ekstrinsik yaitu sistim administrasi yang tidak efisien. Usaha yang keras dan hasil kerja optimal yang telah dicapai seseorang merupakan kunci dari sebuah motivasi dan kepuasan kerja seseorang Kepuasan kerja adalah suatu respon emosional seseorang terhadap berbagai segi pekerjaan ( Kreitner dan Kinicki 2005). Seseorang dapat merasa puas dengan salah satu pekerjaan dan merasa tidak puas dengan pekerjaan lain, tergantung dari kondisi tempat kerja dan hasil pekerjaan yang sesuai dengan yang diharapkan. Kepuasan kerja tidak tampak secara.

Metode : Perawat Indonesia harus dapat memberikan asuhan keperawatan yang komprehensif, mandiri (independen), sehingga pelaksanaannya dapat dipertanggungjawabkan dan dipertanggunggugatkan. ini bertujuan untuk mengetahui pengaruh penerapan standar nursing language terhadap kualitas pengisian dokumentasi keperawatan Perencanaan asuhan keperawatan merupakan kunci dari continuity of care.Dokumentasi perencanaan asuhan keperawatan yang tidak saling berkesinambungan dalam rekam medis berdampak pada kualitas asuhan pasien. Tujuan studi ini adalah menganalisis penyebab fenomena ketidaksinambungan tersebut sehingga dapat memberikan rekomendasi untuk perbaikan bagi pelayanan asuhan keperawatan. Metode yang digunakan adalah studi kasus dengan pendekatan analisis gap antara kondisi yang terjadi dengan kondisi ideal. Studi ini menganalisis fenomena berdasarkan pendekatan fungsi manajemen keperawatan dan metode Ishikawa. Teknik pengumpulan datanya adalah dengan cara wawancara, observasi dan data sekunder dari studi dokumentasi data rumah sakit. Responden dipilih dengan cara tehnik purposive sampling sejumlah sembilan orang manajer keperawatan. Hasil analisis Ishikawa menemukan penyebab utama adalah lembar POC pada awalnya diberlakukan oleh pokja akreditasi rumah sakit sehingga setelah penilaian akreditasi selesai keberlanjutannya terhambat. Selain itu ditemukan juga masalah lain sepertipengetahuan perawat tentang metode penugasan perawat primer, ketenagaan dan supervisi rekam medis POC yang belum optimal. Kesimpulan dari analisis fungsi manajemen keperawatandiperoleh bahwa fungsi pengarahan dan fungsi pengendalian perlu ditingkatkan agar dokumentasi perencanaan asuhan keperawatan lebih optimal. 
Hasil: Diagnosis keperawatan merupakan penilaian klinis terhadap pengalaman atau respon individu, keluarga, dan komunitas pada masalah kesehatan pada resiko masalah kesehatan atau pada proses kehidupan. Diagnosis keperawatan merupakan bagian vital dalam menentukan asuhan keperawatan yang sesuai untuk membantu klien mencapai kesehatan yang optimal. Mengingat pentingnya diagnosis keperawatan dalam memberian asuhan keperawatan, maka dibutuhkan standar diagnosis keperawatan yang dapat diterapkan di indonesia. Penegakan diagnosis keperawatan sebagai salah satu komponen standar asuhan keperawatan perlu dilaksanakan dengan baik sebagaimana yang diamanahkan dalam undang-undang No.38 tahun 2014 tantang keperawatan pada pasal 30 bahwa dalam menjalankan tugas sebagai pemberi asuhan keperawatan, perawat berwenang menetapkan diagnosis keperawatan. Hal ini menegaskan wewenang perawat sebagai penegak diagnosis yang harus memiliki kemampuan diagnosis yang baik sebagai dasar mengembangkan rencana intervensi keperawatan dalam rangka mencapai peningkatan, pencegahan dan penyembuhan serta pemulihan kesehatan klien. Sebuah studi yang dilakukan di Indonesia menunjukkan bahwa $50 \%$ bentuk penilaian keperawatan tidak mengandung informasi lengkap. Sebagian besar dokumen proses keperawatan tidak lengkap, karena persepsi bahwa formulir keperawatan tidak sesuai untuk mendokumentasi kan kebutuhan perawatan pasien. melaporkan bahwa proses dokumentasi tidak mampu menangkap informasi dari diagnosis keperawatan. Studi ini menunjukkan bahwa sedikit atau tidak ada usaha yang dilakukan untuk mengabungkan formulir penilaian dengan diagnosis keperawatan, serta penerapan diagnosis keperawatan di Indonesia. Dokumentasi keperawatan menyita hampir 50\% waktu perawat pershift kebanyakan perawat dalam urutan klinis, tidak melakukan dokumentasi yang lengkap. Alasan mengapa perawat tidak melakukan dokumentasi keperawatan adalah kebanyakan perawat lebih memilih meluangkan waktu untuk melakukan tindakan pada pasien dan tidak mendokumentasikannya. Faktor pekerjaan, pelatihan dan beban kerja. Merupakan faktor yang dapat mempengaruhi kelengkapan dokumentasi keperawatan. Lingkungan kerja, beban kerja yang tinggi, dan sulitnya dokumentasi format waktu pengisian berkontribusi terhadap kurangnya dokumentasi keperawatan. Pada saat melihat rekam medik yang sudah terisi oleh perawat ruangan serta saat peneliti melakukan observasi terdapat ketidak cocokan data yang diambil dengan hasil wawancara perawat ruangan yang menyatakan bahwa diruangan tersebut sering mengangkat diagnosa nyeri yang dialami pasien nyeri yang berat sedangkan ketika peneliti observasi pada pasien diruangan tersebut, didapatkan diagnosa nyeri sering digunakan pada pasien namun tingkat nyeri yang dialami pasien adalah tingkat nyeri ringan dan tanda minor yang muncul hanya dua sampai tiga. Sehingga data yang didapat kurang menunjang dalam penegakan diagnosis, semua diagnosis yang dibuat oleh perawat terlihat sama dan tidak sesuai dengan hasil pengkajian. Berdasarkan latar belakang yang peneliti uraikan, peneliti tertarik untuk meneliti mengenai faktor-faktor yang mempengaruhi penegakan standar diagnosis keperawatan. 
Pembahasan: Diagnosa keperawatan adalah suatu pernyataan yang menjelaskan respons manusia (status kesehatan atau resiko perubahan pola) dari individu atau kelompok dimana perawat secara akuntabilitas dapat mengidentifikasi dan memberikan intervensi secara pasti untuk menjaga status kesehatan menurunkan, membatasi, mencegah, dan merubah (a Carpenito, 2000) . Gordon (1976) mendefinisikan bahwa diagnosa keperawatan adalah "masalah kesehatan actual dan potensial dimana perawat berdasarkan pendidikan dan pengalamannya, dia mampu dan mempunyai kewenangan untuk memberikan tindakan keperawatan". Kewanangan tersebut didasarkan pada standar praktek keperawatan dan etik keperawatan yang berlaku di Indonesia.NANDA menyatakan bahwa diagnosa keperawatan adalah "keputusan klinik tentang respon individu, keluarga dan masyarakat tentang masalah kesehatan aktual atau potensial, sebagai dasar seleksi intervensi keperawatan untuk mencapai tujuan asuhan keperawatan sesuai dengan kewenangan perawat". Semua diagnosa keperawatan harus didukung oleh data, dimana menurut NANDA diartikan sebagai "defenisi karakteristik". Definisi karakteristik tersebut dinamakan "Tanda dan gejala", Tanda adalah sesuatu yang dapat diobservasi dan gejala adalah sesuatu yang dirasakan oleh klien. Diagnosa keperawatan menjadi dasar untuk pemilihan tindakan keperawatan untuk mencapai hasil bagi anda, sebagai perawat, yang dapat diandalakan(NANDA Internasional, 2007).Diagnosa keperawatan berfokus pada, respon aktual atau potensial klien terhadap masalah kesehatan dibandingkan dengan kejadian fisiologis, komplikasi, atau penyakit. Adapun tujuan Pencatatan Diagnosa Keperawatan :Menyediakan definisi yang tepat yang dapat memberikan bahasa yang sama dalam memahami kebutuhan klien bagi semua anggota tim pelayanan kesehatan, Memungkinkan perawat untuk mengkomunikasikan apa yang mereka lakukan sendiri, dengan profesi pelayanan kesehatan yang lain, dan masyarakat, Membedakan peran perawat dari dokter atau penyelenggara pelayanan kesehatan lain, Membantu perawat berfokus pada bidang praktik keperawatan, Membantu mengembangkan pengetahuan keperawatan. kemampuan pengetahuan perawat dalam menentukan diagnosis keperawatan spiritual adalah mampu menganalisis untuk menentukan diagnosis spiritual yang berhubungan dengan perubahan pola hidup akibat penyakit ( $88 \%$ ), namun masih banyak ( $\geq 50 \%$ ) yang belum mampu membedakan (C3) antar diagnosis spiritual seperti risiko distress spiritual, resiko hambatan religiusitas, berduka antisipatif, konflik pengambilan keputusan, distress spiritual, berduka disfungsional, kesejahteraan spiritual dan ansietas kematian. Standar Diagnosis Keperawatan Indonesia (PPNI, 2017) menunjukan definisi dan faktor- faktor yang berhubungan dengan diagnosis keperawatan spiritual untuk berduka, distress spiritual, berduka, dan resiko distress spiritual, sementara diagnosis keperawatan spiritual untuk resiko hambatan religiusitas, berduka antisipatif, konflik pengambilan keputusan, berduka disfungsional, kesejahteraan spiritual dan ansietas kematian dijelaskan pada (NANDA, 2018). Definisi dari setiap diagnosis keperawatan spiritual tersebut sebenarnya memiliki kata kunci yang perlu diperhatikan oleh perawat. Perbedaan diagnosis spiritual pada resiko distress spiritual, distress spiritual dan 
kesiapan peningkatan kesejahteraan spiritual adalah pada kemampuan memaknai situasi yang terjadi pada individu tersebut serta koneksivitas individu dengan sumber spiritualnya dalam bentuk ibadah atau ritual agama. keperawatan (nursing process) sebagai kerangka pikir dan kerangka kerja dalam merawat pasien. Keperawatan sebagai proses terdiri dari assessment (pengkajian), diagnosis (penetapan diagnosa), planning outcomes (perencanaan hasil), planning intervention (perencanaan intervensi), implementation (implementasi) dan evaluation (evaluasi) (Wilkinson, J., M 2007). Pada prakteknya kegiatan proses keperawatan di atas tidaklah selalu berurutan tetapi bisa dikerjakan pada waktu bersamaan/tumpang tindih (overlapping). Pengalaman menunjukkan bahwa sering sekali perawat kesulitan dalam menentukan diagnosa karena pengkajian yang dilakukan oleh perawat tidak mempunyai urutan yang efektif dan terstruktur (Nurjannah, I. 2012.). Diagnosa keperawatan mengintegrasikan keterlibatan pasien, jika memungkinkan, di seluruh proses. NANDA International (NANDA-I) adalah badan profesional yang mengembangkan, meneliti dan menyempurnakan taksonomi resmi diagnosis keperawatan. Semua perawat harus terbiasa dengan langkah-langkah proses keperawatan untuk mencapai efisiensi dalam menjalankan profesi mereka. Untuk mendiagnosis dengan benar, perawat harus membuat kesimpulan cepat dan akurat dari data pasien selama penilaian, berdasarkan pengetahuan tentang disiplin keperawatan dan konsep yang menjadi perhatian perawat. Setelah menyelesaikan pengkajian keperawatan, perawat melanjutkan pada diagnosa keperawatan,yang merupakan penilaian klinis tentang respons individu,keluarga,atau kamunitas terhadap masalah kesehatan aktual atau potensial atau proses kehidupan.diagnosa keperawatan adalah pernyataan yang menggambarkan respon aktual atau potensial klien terhadap masalah kesehatan yang perawat mempunyai lisensi dan kompeten untuk mengatasinya.

Diagnosa keperawatan memberikan dasar untuk pemilihan intervensi untuk mencapai hasil yang menjadi tanggung gugat perawat (NANDA,1990; Carpenito,1993). Hasil dan intervensi dipilih dalam kaitannya dengan diagnosa keperawatan tertentu (McCloskey \& Bulechek,1992). Alasan untuk merumuskan diagnosa keperawatan setelah menganalisis data pengkajian adalah untuk mengidentifikasi masalah kesehatan yang melibatkan klien dan keluarganya dan untuk memberikan arah asuhan keperawatan.pernyataan diagnosa keperawatan adalah hasil dari proses diagnostik selama perawat menggunakan pemikiran kritis, diagnosa kepearawatan dikembangkan untuk klien,keluarga, atau komunitaas dan mencakup data fisik perkembangan, intelektual, emosi, sosial dan spiritual yang didapapatkan selama pengkajian. Adapun Fungsi analisis : Dapat menginterpretasi data keperawatan dan kesehatan, sehingga data yang diperoleh memiliki makna dan arti dalam menentukan masalah dan kebutuhan klien dan Sebagai proses pengambilan keputusan dalam menentukan alternatif pemecahan masalah yang dituangkan dalam rencana asuhan keperawatan, sebelum melakukan tindakan keperawatan. 
1. Diagnosa Keperawatan Aktual: Diagnosa keperawatan aktual menurut NANDA adalah diagnosa yang menyajikan keadaan klinis yang telah divalidasikan melalui batasan karakteristik mayor yang diidentifikasi. Diagnosa keperawatan mempunyai empat komponen : label, definisi, batasan karakteristik, dan faktor yang berhubungan. Label merupakan deskripsi tentang definisi diagnosis dan batasan karakteristik. Definisi menekankan pada kejelasan, arti yang tepat untuk diagnosa. Batasan karakteristik adalah karakteristik yang mengacu pada petunjuk klinis, tanda subjektif dan objektif. Batasan ini juga mengacu pada gejala yang ada dalam kelompok dan mengacu pada diagnosis keperawatan, yang teridiri dari batasan mayor dan minor. Faktor yang berhubungan merupakan etiologi atau faktor penunjang. Faktor ini dapat mempengaruhi perubahan status kesehatan. Faktor yang berhubungan terdiri dari empat komponen : patofisiologi, tindakan yang berhubungan, situasional, dan maturasional. Penulisan rumusan diagnosis ini adalah : PES (problem + etiologi + simtom).

2. Diagnosa Keperawatan Risiko atau Risiko Tinggi : Menurut NANDA, diagnosa keperawatan risiko adalah keputusan klinis tentang individu, keluarga atau komunitas yang sangat rentan untuk mengalami masalah dibanding individu atau kelompok lain pada situasi yang sama atau hampir sama.Diagnosa keperawatan ini mengganti istilah keperawatan potensial dengan menggunakan "risiko terhadap atau risiko tinggi terhadap". Validasi untuk menunjang diagnosis resiko tinggi adalah faktor resiko yang memperlihatkan keadaan dimana kerentanan meningkat terhadap klien atau kelompok dan tidak menggunakan batasan karakteristik. Penulisan rumusan diagnosis ini adalah : PE (problem \& etiologi).

3. Diagnosa Keperawatan Kemungkinan: Menurut NANDA, diagnosa keperawatan kemungkinan adalah pernyataan tentang masalah yang diduga masih memerlukan data tambahan dengan harapan masih diperlukan untuk memastikan adanya tanda dan gejala utama adanya faktor resiko.

4. Diagnosa Keperawatan Sejahtera: Menurut NANDA, diagnosa keperawatan sejahtera adalah ketentuan klinis mengenai individu, kelompok, atau masyarakat dalam transisi dari tingkat kesehatan khusus ke tingkat kesehatan yang lebih baik. Cara pembuatan diagnosa ini adalah dengan menggabungkan pernyataan fungsi positif dalam masing-masing pola kesehatan fungsional sebagai alat pengkajian yang disahkan. Dalam menentukan diagnosa keperawatan sejahtera, menun jukkan terjadinya peningkatan fungsi kesehatan menjadi fungsi yang positif.

5. Diagnosa Keperawatan Sindrom: Menurut NANDA, diagnosa keperawatan sindrom adalah diagnosa yang terdiri dari sekelompok diagnosa keperawatan aktual atau resiko, yang diduga akan muncul karena suatu kejadian atau situasi tertentu. Menurut NANDA ada 2 diagnosa keperawatan sindrom 
1. Sindrom trauma pemerkosaan : Contoh cemas, takut, sedih, gangguan pola istirahat dan tidur.

2. Resiko sindrom penyalahgunaan: Contoh Resiko Konstipasi, Resiko perubahan fungsi pernafasan, Resiko infeks, Resiko gangguan aktifitas

\section{Penutup:}

masyarakat tentang masalah kesehatan aktual atau potensial, dimana berdasarkan pendidikan dan pengalamannya, perawat secara akontabilitas dapat mengidentifikasi dan memberikan intervensi secara pasti untuk menjaga, menurunkan, membatasi, mencegah dan merubah status kesehatan klien (Carpenito, 2000; Gordon, 1976 \& NANDA).

Diagnosis keperawatan ditetapkan berdasarkan analisis dan interpretasi data yang diperoleh dari pengkajian keperawatan klien. Diagnosis keperawatan memberikan gambaran tentang masalah atau status kesehatan klien yang nyata (aktual) dan kemungkinan akan terjadi, dimana pemecahannya dapat dilakukan dalam batas wewenang perawat.

\section{Daftar pustaka:}

1. Simamora, R. H., Bukit, E., Purba, J. M., \& Siahaan, J. (2017). Penguatan kinerja perawat dalam pemberian asuhan keperawatan melalui pelatihan ronde keperawatan di rumah sakit royal prima medan. Jurnal pengabdian kepada masyarakat, 23(2), 300-304.

2. Simamora, R. H. (2019). Socialization of Information Technology Utilization and Knowledge of Information System Effectiveness at Hospital Nurses in Medan, North Sumatra. Editorial Preface From the Desk of Managing Editor..., 10(9).

3. Muhamad Rofi'i, Bambang Edi Warsito, \& Agus Santoso.2018.Diagnosa Keperawatan Yang Sering Ditegakkan Perawat Pada Pasien Tuberkulosis Paru Di Rumah Sakit. Jurnal kepemimpinan dan manajemen keperawatan.VOL 1. NO 2. HAL 1-7.

4. Purnama Christina, Agustin Indracahyani \& Aat Yatnikasaria. 2019.Analisis Ketidaksinambungan Dokumentasi Perencanaan Asuhan Keperawatan : Metode Ishikawa. Jurnal IImiah Kesehatan (JIK) Vol XII, No II. HAL 518-524 
5. Inggriane Puspita Dewi, Nurrohmah \& Fikri Rizki Fadlurrahman.2020.Analisis Pengetahuan Perawat dalam Menentukan Diagnosis Asuhan Keperawatan Spiritual Islami di Rumah Sakit Syariah. Jurnal IImiah Keperawatan Indonesia.

Vol 4, No 1. Hal 73-85

6. Raudhatul Jannah, Dwiharini Puspitaningsih \& Eka Diah Kartiningrum.2019.ASUHAN KEPERAWATAN PADA PASIEN DENGAN DENGUE HAEMORRAGIC FEVER (DHF) DI RUANG JAYANEGARA RSU. Dr. WAHIDIN SUDIROHUSODO MOJOKERTO. Hospital majapahit. VOL 11.NO 02. Hal 40-47

7. Fitri Mailani \& Indri Ramadini.2018.PEDAMPINGAN DAN PELATIHAN PENDOKUMENTASIAN KEPERAWATAN DI PUSKESMAS LUBUK BUAYA PADANG. Jurnal Abdimas Saintika.vol 1.NO 1.HAL 5-13

8. Farida Nuraini.2016.RANCANG BANGUN SISTEM INFORMASI DIAGNOSA KEPERAWATAN AKTUAL PADA PENDERITA DIABETES MELITUS. Jurnal Teknologi Informasi Vol . XI Nomor 31.hal 1-7

9. Hidayah, Nur (2014).Manajemen Model Asuhan Keperawatan Profesional (MAKP) Tim Dalam Peningkatan Kepuasan Pasien Di Rumah Sakit. Jurnal Kesehatan Vol 1. No. 2; 410-426.

10. Putri Wulandini. S.a, Tri Kriantob \& Yuyun Priwahyuni.2016.FAKTOR-FAKTOR YANG BERHUBUNGAN DENGAN PENDOKUMENTASIAN ASUHAN KEPERAWATAN DI RUMAH SAKIT JIWA. NERS JURNAL KEPERAWATAN,Volume 12, No.2, (Hal.131-142)

11. Erna Dwi Wahyuni, Candra Panji Asmoro dan Endang Susiana.2019.Faktor yang Berhubungan dengan Mutu Pendokumentasian Asuhan Keperawatan (Factors Related to the Quality of Nursing Care Documentation). FUNDAMENTAL AND MANAGEMENT NURSING JOURNAL.Vol. 2, No. 1 HAL 16-23

12. Yana Hendriana \& Aria Pranatha.2019.Standar nursing language berbasis NANDA, NOC, dan NIC terhadap kualitas pengisian dokumentasi keperawatan. Jurnal Penelitian dan Pemikiran IImiah Keperawatan. Volume 5, Issue 2, Pages 26-31 
